\title{
SCAN-TO-BIM vS 3D IDEAL MODEL HBIM: PARAMETRIC TOOLS TO STUDY DOMES GEOMETRY
}

\author{
M. Capone ${ }^{1}$, E. Lanzara ${ }^{1}$ \\ ${ }^{1}$ UNINA, University of Naples Federico II - (mara.capone, emanuela.lanzara)@unina.it
}

Commission II

KEY WORDS: Procedural Modeling, HBIM, Domes, Parametric tools.

\begin{abstract}
:
The contribution is part of an interdisciplinary research that aims to address the problems of knowledge, interpretation and documentation of vulnerable structures such as the brick Renaissance domes in Campania (XV-XVI century). The goal is to analyze the relationship between Survey, Historic Building Information Modelling (HBIM) and 3D parametric models based on geometric rules from Treaties to study and to manage Cultural Heritage. HBIM is generally based on scan-to-BIM process that allows to generate 3D model from point cloud. The reverse modeling process, from a point cloud to parametric geometric model, poses a series of issues at the center of cultural debate that currently takes place around HBIM. The experimentation underway is part of this research field with the aim of using the parametric approach as a tool able to introduce an additional methodology for big data interpretation. Currently we can identify two different approaches for the construction of a HBIM system: building a simplified model by identifying the shape grammar or building the geometric components from survey without using pre-compiled objects libraries, following the scan to BIM logic. In our research we are going to identify an "hybrid" methodology. Generally the process is based on the knowledge and critical abilities of individual scholars, the idea is to increase the efficiency of the system through collaborative workflow forms that allow to optimize the processes through effective knowledge management actions. We are going to use procedural modeling techniques to generate HBIM domes library.
\end{abstract}

\section{INTRODUCTION}

The contribution is part of an interdisciplinary research that aims to address the problems of knowledge, interpretation and documentation of particularly vulnerable structures such as the brick Renaissance domes in Campania (XV-XVI century). The goal is to analyze the relationship between Survey, Historic Building Information Modelling (HBIM) and 3D parametric models based on geometric rules from Treaties to study and to manage Cultural Heritage.

Geometry has always been an irreplaceable tools to transform spatial ideas into a feasible project.

Until the end of the seventeenth century, when analytical methods of calculation spread also in Italy, the structural sizing of the fundamental elements of construction, arches, vaulted systems, domes, was based on proportional relationships between the parts, on the rules deduced from experience and, above all, from the analysis of the numerous collapses.

In the architectural treatises we can identify two different trends: one based on geometric sizing and the other on constructive practice, the latter anticipated by Alberti in his treatise of 1450 (Marconi 1997).

Dome model of the fifteenth and sixteenth centuries is an element that, while preserving the symbolic meaning of ascent, is independent of the underlying structure. The Renaissance dome is often a crowning achievement of the architectural organism, often designed and built at different times. Starting from hemispheric dome on pendentives complex solutions are developed to accentuate the vertical development: insertion of a drum and meridian geometry change.

From a methodological point of view, the deconstruction of the architectural organism object of study, in its plastic and
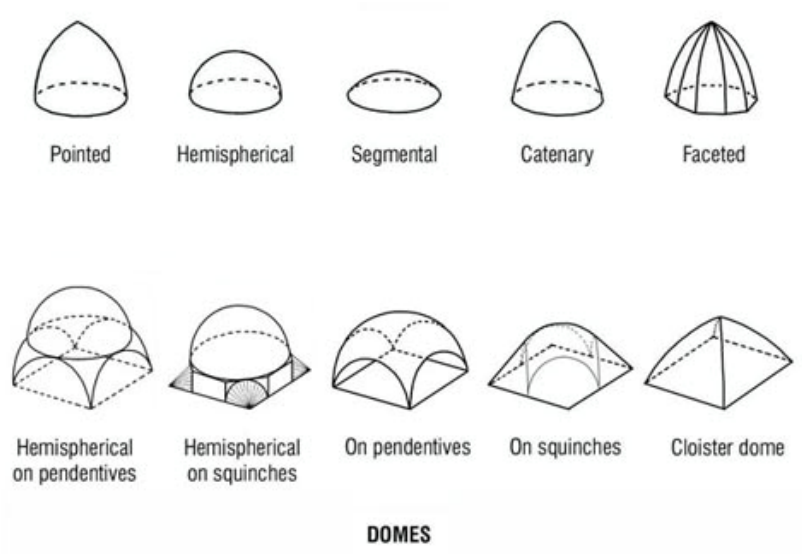

Figure 1. Geometric Domes classification, shape grammar

geometric elements, is the starting point for the definition of the variables of the parametric model that we are testing. The semantic classification of architectural elements, before the modelling phase, is a fundamental step in order to avoid create objects meaningless from an architectural point of view (Bruno 2017). The search for "generating geometries" (Migliari 2014), sometimes hidden by decorative elements, it is crucial to be able to see beyond the visible. Geometrical knowledge becomes fundamental especially for big data interpretation, in the process that from the point cloud allows to define a synthetic geometric model. Our goal is to define a parametric tool that introduces a further step in the traditional process "scan to BIM". The use of BIM for new buildings is characterized by standard procedures and methodologies, instead use of BIM for Cultural Heritage is an innovative and still underdeveloped research field. 
In our research we have defined an experimental HBIM workflow with the aim of generating set of dome library based on the geometric rules from treatises, the comparison of these 3D models with point clouds allows to identify the rule used or to define a new rule and, therefore, to build complex parametric models based on reality-based surveys.

\section{DOMES GEOMETRY RULES}

\subsection{Circular domes}

Domes are double curvature surfaces, the most common domes spring from a circular base and for that we call them "circular domes", even if their cross-section is not circular. Circular domes are revolution surfaces generated by rotating a meridian curve around a vertical axis. In this part of our research we have analyzed geometric genesis of the meridian curve.

From the analyzed examples and from the study of the treatises we have identified three kinds of domes: domes with meridian curve composed by a quarter of circle, in this case they are "hemispherical domes", domes with meridian curve composed by a pointed arc or polycentric arcs, "pointed domes". There are few cases of domes generated by parabolic, elliptic or catenary curves.

Need to provide simple indications for building has determined definition of rules which, through fundamental parameters, allow proportionality criteria translation into construction instructions. Dimensional ratios for domes construction are based on proportionality criteria between different elements thickness, lantern, drum - that are generally expressed as a diameter function. Geometric sizing was used until the end of the seventeenth century, when the analytical calculation replaced geometry (Marconi 1997).

\subsection{Geometric rules from Treatises}

In our research we analyzed some of the geometric methods described in Treatises with the aim to compare the theoretical model with the real based model.

With regard to hemispherical domes we have analyzed the methods illustrated by Andrea Palladio in the Four Books of Architecture, by Sebastiano Serlio in Book V of the Seven Books of Architecture, while pointed-domes were compared with the constructions illustrated by Carlo Fontana, by B.A. Vittone and by Vincenzo Scamozzi. Theoretical models defined according to treaties study have been compared with case studies in Campania. This comparison allows us to do a critical analysis based on geometric rules.
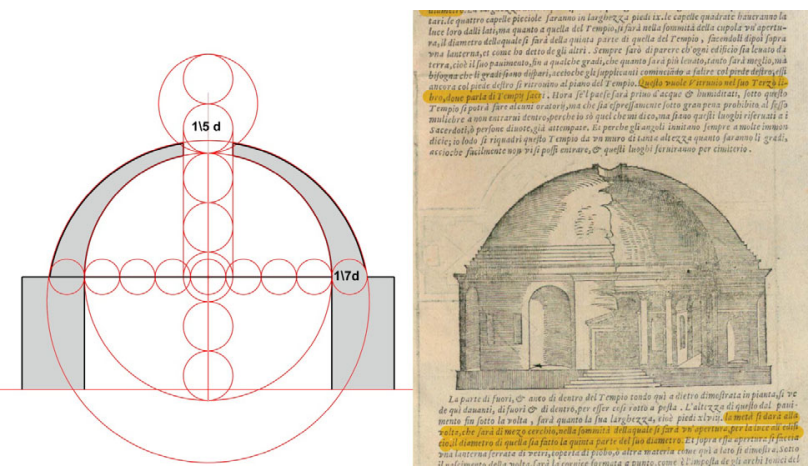

Figure 2. Sebastiano Serlio, Sette libri di Architettura, Libro V, Venezia 1584.

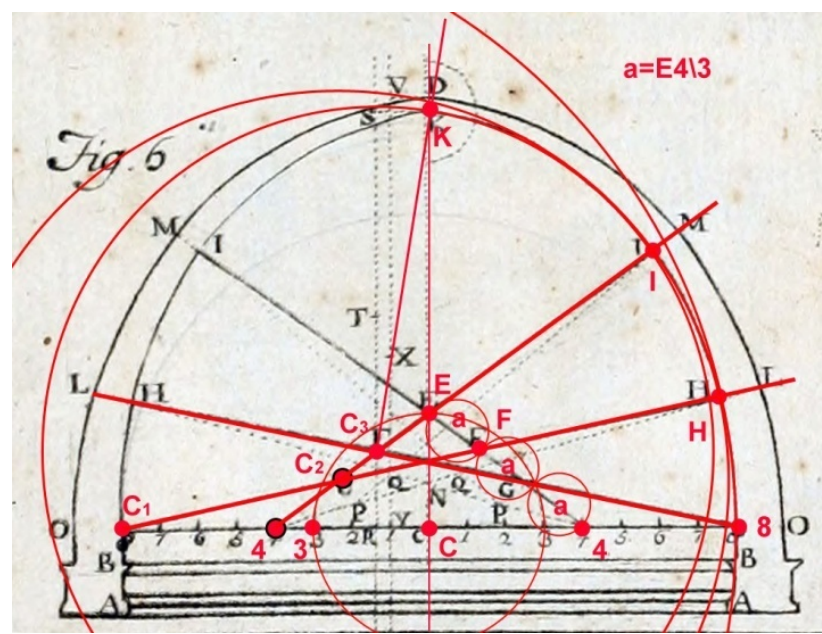

Figure 3. B. A. Vittone, Regole per il dimensionamento geometrico delle cupole (Istruzioni elementari per l'indirizzo dei giovani allo studio dell'architettura, 1760)

Geometric rules for domes sizing are always deduced from observation and survey of real examples. In addition to treaties by Serlio, Fontana and Vittone, we are going to study other treatise, in particular Alberti, Palladio and Scamozzi, with the aim of using computational modeling to compare theoretical approach with real architecture.

From a methodological point of view we have tried to build a unique parametric model able to connect the different processes, using the same parameter: the diameter.

By comparing this model with point clouds, it is possible to evaluate analogies or identify new rules that will be used to develop a more complex parametric model based on surveys.

\section{SCAN-TO-BIM VS 3D PROCEDURAL MODELING}

"Historic Building Information Modelling (HBIM) is a novel prototype library of parametric objects, based on historic architectural data, in addition to a mapping system for plotting the library objects onto laser scan survey data"( Murphy 2012). The realization of an information system for Cultural Heritage knowledge and preservation has to take into account several aspects that are not relevant in a BIM for new constructions. First of all, the HBIM process is opposite: it starts from the real object not from ideal model, and the model is an abstraction of the reality (Bruno 2017).

It is a process that takes place from transforming point cloud (big data) into 3D model (Yang et. al 2018).

\subsection{D modelling techniques for Cultural Heritage}

The main modeling techniques, using to generate $3 \mathrm{D}$ model from point cloud, can be generally classified into four groups: "reverse modeling", "direct modeling", "generative modeling" and "Parametric object oriented modeling" (Bruno 2017).

Using one of the reverse modeling tools (commercial or open source) we can automatically translate the point cloud into polygonal mesh surface, continuous surface into polyhedral object. We can represent complex objects using meshes but they are not able to describe geometric rules (Bruno 2017).

Using "direct modeling" technique we have to define the main profiles of the object (for example horizontal and vertical profiles) necessary for reconstructing complex shapes. 


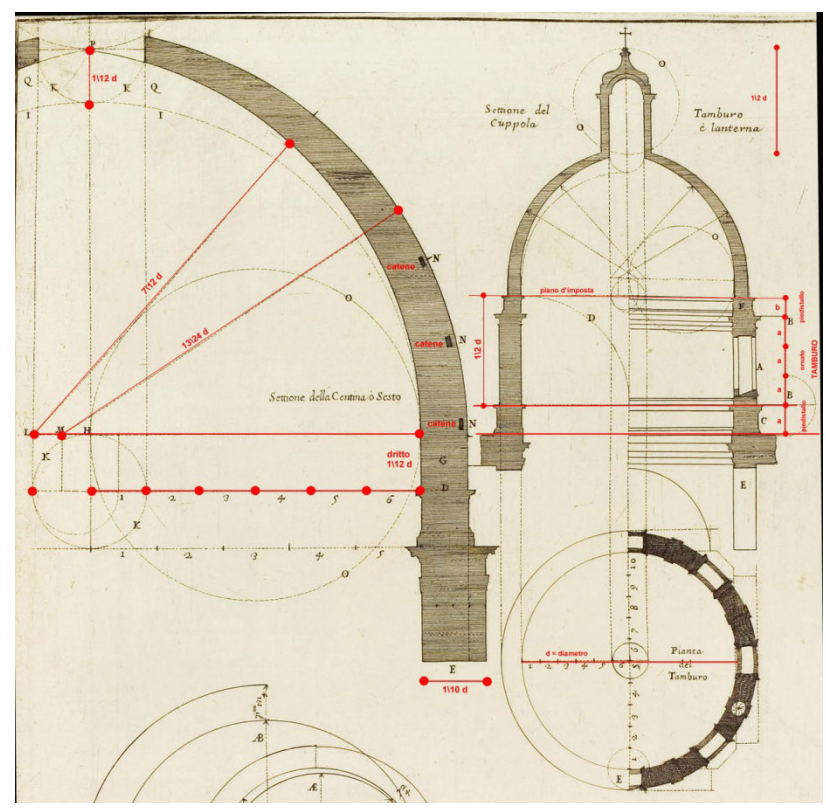

Figure 4. Carlo Fontana, Dimostrazioni e regole per costruire le Cupole semplici e Dimostrazioni e regole per costruire le Lanterne"

We can generate the interpolated surface starting from these profiles using one of the $3 \mathrm{D}$ modeling software, such us as Rhinoceros (Bruno 2017).

We can use Grasshopper (plug-in for Rhino) or Dynamo (plugin for Revit) to generate $3 \mathrm{D}$ parametric models based on geometric rules. This 3D modeling technique is "generative modeling" process, in this case the choice of parameters is crucial.

"Parametric object oriented modeling" consists in the use of pre-modeled objects collected in libraries. This is the typical approach for BIM software, in the case of HBIM we have to generate parametric objects library that we can change in relation to point cloud to recognize the geometric rule.

In our research we first studied the process to create parametric objects based on various works above Architectural Orders (Aubin 2014) and then we have generated parametric domes library. The main goal is to generate fully scalable 3D models in relation to architectural rules but that can be modify in relation to real architecture.

\subsection{Generating parametric objects library from historical data}

HBIM is generally based on scan-to-BIM process that allows to generate 3D model from point cloud. Parametric tools can reduce human involvement in $3 \mathrm{D}$ modeling process, the goal is to develop a pipeline that allows to become this process increasingly automatic. The question is how to check an automatic process without losing the main features of Cultural Heritage.

One of the main problems to address in the study and management of the historical heritage is the relationship between the real model, the synthetic geometric model, deriving from the interpretation of big data, and the ideal model. Generally, the point cloud is semantically decomposed in a 3D model derived from data simplification: synthetic geometric model. This process is not only automatic, but it is strongly conditioned by the knowledge of the operator or by the analytical tools that the operator has in order to be able to decode historical data. The reverse modeling process, from a point cloud to parametric geometric model, poses a series of issues at the center of cultural debate that currently takes place around HBIM, Historic Building Information Modeling (Paris et al. 2016). The experimentation underway is part of this research field with the aim of using the parametric approach as a tool able to introduce an additional methodology for big data interpretation.

Currently we can identify two different approaches for the construction of a HBIM system: building a simplified model by identifying the shape grammar or building the geometric components from survey without using pre-compiled objects libraries, following the scan to BIM logic.

Two problems existed for researchers in generating HBIM, the first is the absence of complex historic architectural elements in BIM libraries and secondly a system for mapping the objects onto remotely sensed survey data (Dore 2015).

First we have to identify the architectural rules and shape grammars, which we can be applied to develop the library of historical Architectural Elements, this information can be found in various historic architectural texts (Dore 2015) and then we have to choose the parameters that we can use to modify the object, the procedural rules.

In our research we are going to identify an "hybrid" methodology.

Traditional approach begins with analysis of main data, from the point cloud, which can be used to provide thematic readings. You can operate directly on the cloud, using a color code to associate certain properties, you can highlight parts of the building that have the same characteristics and then add annotations. In this way the points cloud, from an anonymous set of points, acquires a meaning and it could become interface of an information system. Obviously this process is not automatic, just as the transformation of the points cloud into a geometric model divided into elements, each with certain characteristics, is not automatic.

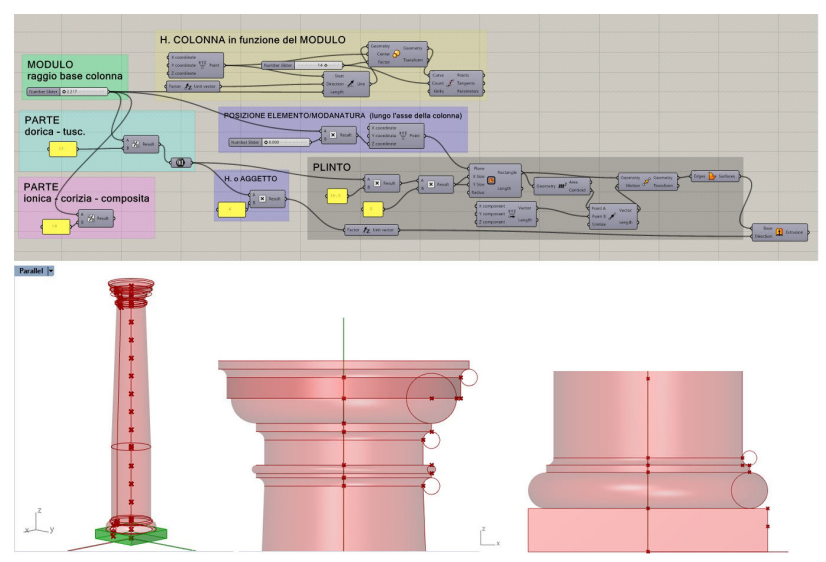

Figure 5. Parametric modeling for Architectural Orders

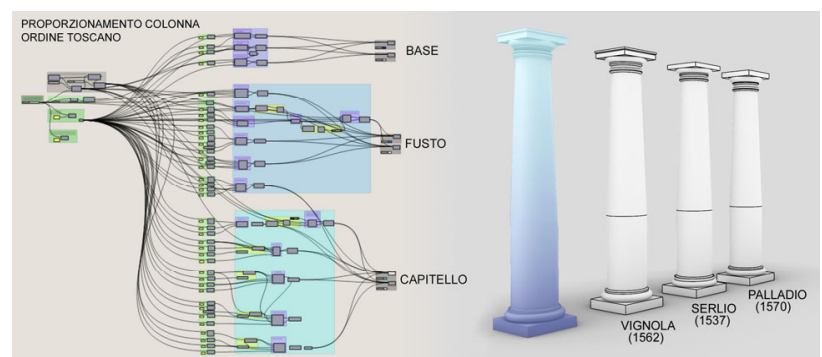

Figure 6. Parametric modeling for Architectural Orders 


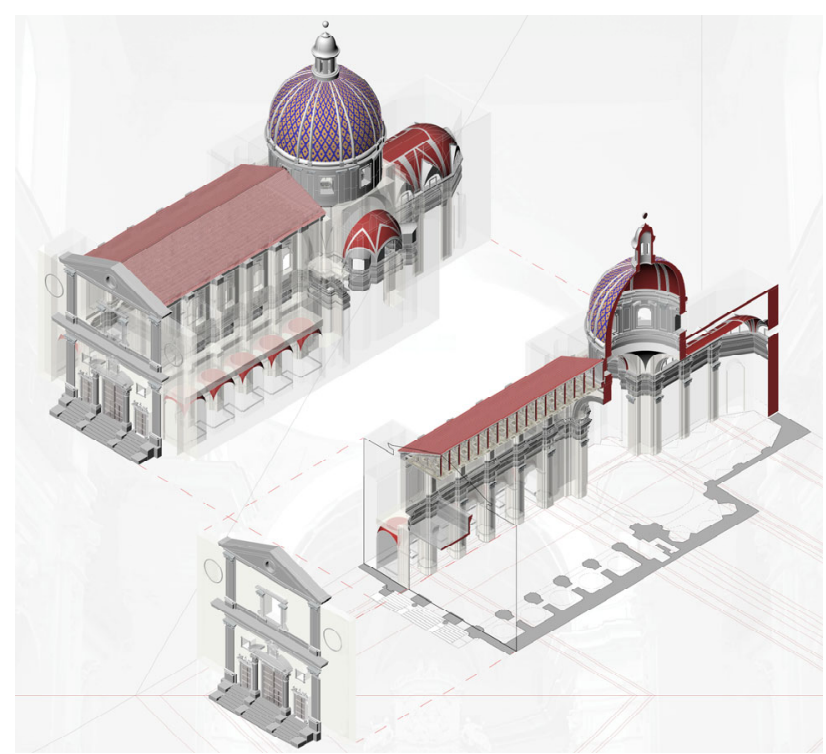

Figure 7. - Architectural Elements definition. Napoli, S. Maria di Costantinopoli Church

You generally use libraries of parametric objects that you have to overlap to point cloud, until the resemblance is satisfactory, to build a simplified 3D geometric model.

Therefore, the synthetic geometric model inevitably deviates from reality, approximating it in the best way. However, for each single simplified element it is possible to link other detailed information, specific 3D models, which allow to evaluate its status. If, for example, within the artifact there are a series of Doric columns, in the simplified model the columns will all be the same, and they will be taken from the parametric library, but you can associate each of them with the real based 3D model of detail, built from the point cloud without simplifications. In this way we can analyze all possible anomalies and gaps and we can document both the construction practice and the state of conservation.

Algorithmic modeling use is fundamental in the context of HBIM processes as it allows to build forms through rules and historical architecture is often the result of rules application defined by manuals. Parametric models construction, based on geometric rules by Treatises, is the first step to build a library of ideal models, that can be overlapped on point cloud, to analyze the geometric configuration.

\subsection{HBIM - big data interpratation}

This approach allows to acquire a deep knowledge of the building that goes beyond the visible, with the aim of discovering the founding principles of the construction.

The overlapping of ideal models to $3 \mathrm{D}$ realty based model is a fundamental tool for comparing, analyzing data, processing critical interpretations, identifying rules and understanding exceptions.

The evolution of surveying and modeling tools aimed at the automation of many processes promotes the diffusion of a different approach, called scan-to-BIM, which is based on the construction of 3D realty based models, which document the actual situation. Often the conversion of laser survey data into complex 3D models is based on the use of very advanced technologies, that are prerogative of specialized technicians. They don't interpret the data through a critical analysis work, but rather they have to build a digital model that reflects reality in the most objective way is possible.
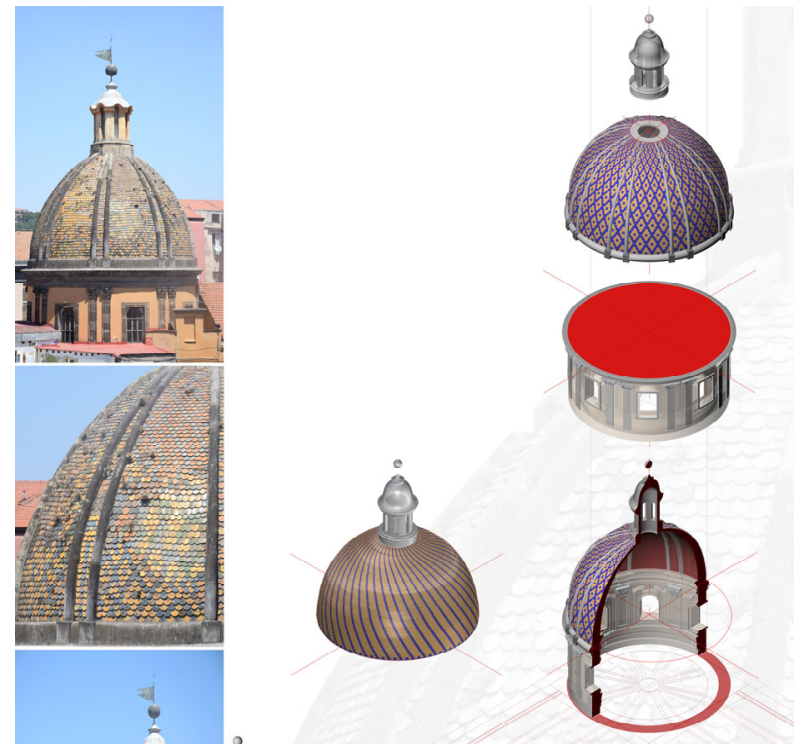

Figure 8. Semantic classification, Architectural Elements definition. Napoli, S. Maria di Costantinopoli Church

This model, which can therefore be defined as realty based, represents data that will have to be analyzed, interpreted by specialists in the various sectors with the aim of knowing the multiple components of the building, from the geometric rules to the construction aspects.

3D realty based model is, therefore, the starting point for the construction of a system based on sharing of knowledge, which allows a collaborative workflow, within which individual knowledge can be conveniently archived and always available, so to be used thanks to a correct knowledge management action. Fundamental in this process is to ensure the interoperability of digital model so that each actor involved in the process of knowledge, protection or enhancement, can always have access to all information associated with it. The use of parametric tools is the choice of open non-proprietary formats, thus becoming a crucial step, as it guarantees access to data in the long run without present and future uncertainty.

The workflow based on the computational approach that we are experimenting in our research includes the following activities:

1. Domes parametric models based on treaties rules;

2. data acquisition (point cloud from laser scanning or photogrammetry);

3. overlapping of ideal parametric model to point cloud;

4. construction of the realty based model (without semantic annotations);

5. critical interpretation of data (geometric configuration hypothesis and identification of new rules);

6 . generation of complex parametric models based on realitybased surveys (with semantic annotations based on the identified geometric rules);

7. construction of interoperable geometric model to be used both as an interface to a 3D communication system and as part of a HBIM system.

Generally this process is based on knowledge and analytical and critical abilities of individual scholars, the idea is to increase the efficiency of the system through collaborative workflow forms that allow to optimize the processes through effective knowledge management actions.

Our specific contribution in this process was to build a parametric model based on treaties rules. The main effort is to construct a unique parametric model in order to relate the different geometric procedures. 


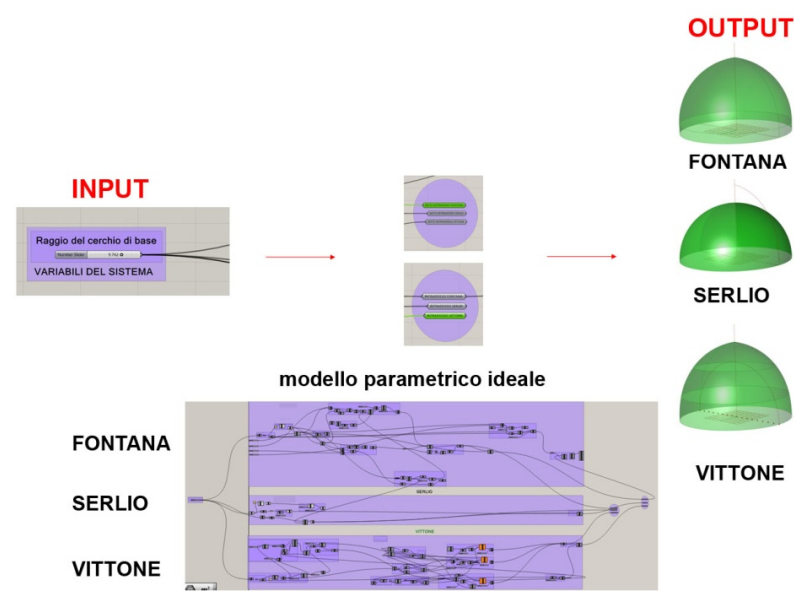

Figure 9. construction of parametric models based on treaties Domes parametric models based on treaties rules by Fontana, Serlio e Vittone.

Through this instrument, by inserting the diameter measurement or some other parameters, different configurations can be obtained according to geometric rule used.

Comparing these configurations with point cloud you can evaluate which is the one that most coincides with reality.

In the event that none of parametric models is similar to the real dome, we have to search for a different rule, taking also into account the constructive modalities. The possible identification of new rules derived from the study of case study is the basis for building other parametric models that can be used as analysis tools.

In this way the system is implemented by adding new parametric models derived from the observation of the reality, therefore, following a consolidated and historically practice by treatises.

In other words, knowledge process aims to construction of a freely usable and open analysis tool with the goal of experimenting a collaborative system based on the sharing of knowledge.

\section{PARAMETRIC TOOLS TO STUDY DOMES GEOMETRY}

\subsection{Parametric tools and procedural modeling}

Parametric modeling is progressively replacing traditional $3 \mathrm{D}$ modeling techniques, opening new research areas both for design and for historical heritage study.

Unlike traditional modeling methods the representation is replaced by simulation and the study of computational variables allows to control design process and rules understanding. Through rules computation you can generate different solutions in relation to parameters appropriately chosen as a reference and that, therefore, meet criteria used to build the model.

There are elements, such as architectural orders, that can be easily converted into parametric models because they are generated using rules and proportions (Valenti et al.2012). These shapes are governed by replacement rules whereby a shape can be changed or replaced by transformations and deformations (Murphy 2012).

The architectural orders are complemented by other structural and decorative elements and so we have to analyze geometric matrices to generate an adaptable parametric model (Paris et al. 2016).

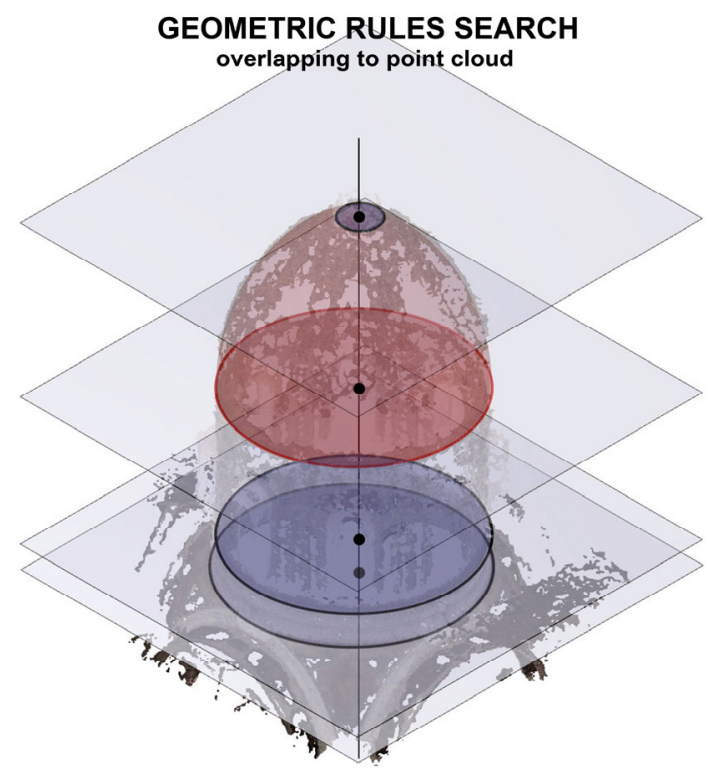

Figure 10. Napoli, S. Maria di Costantinopoli Church: rules search

When the parametric objects are used in the HBIM platform, they can be transformed and deformed to match real world requirements (Murphy 2012).

There are a lot of scientific works about the use of Classical modular relationships to generate parametric model for procedural Historic Building Information Modelling (Dore 2017) but it is more difficult defining the shape grammar for complex surfaces such us vaults and domes.

Architectural rules and proportions are also used to assist the reconstruction process. They can be used to provide an initial estimate for the position and size of building elements on a generated building. This greatly reduces the amount of further editing required when modelling classical buildings from survey data (C. Dore 2015). We think that procedural modelling is a suitable solution for more accurate, automated and easier generation of BIM geometry from point clouds (Dore 2017).

\subsection{Domes procedural modeling}

As part of this research we are creating a parametric tool to study and understand the historical architecture and specifically the dome system.

Using generative algorithmic modeling we have built parametric models based on the geometric rules described by Serlio, Fontana, Vittone and Scamozzi.

The goal is to relate the different processes by identifying the same appropriately chosen reference parameter. This system makes it possible to determinate the generatix curve of the inside surface, the lantern and to size all those elements the dome is composed of (drum, decoration...).

Our research in progress tends to identify parametric model that is a flexible tool to be used not only to control the project but to understand reality.

In fact, the possibility of implementing this tool, adding further procedures based on treaties or rules derived from case studies, allows to structure an open system, able to promote dissemination of knowledge and to facilitate geometric genesis interpretation of the domes structure.

Parametric objects describe a model with a finite number of parameters, such as length, height, thickness, radius etc. 


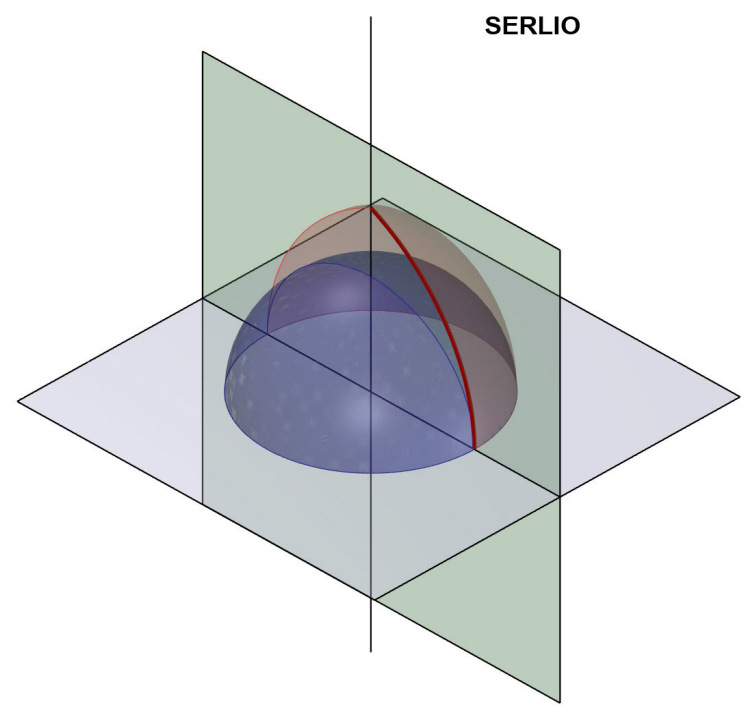

Figure 11. Napoli, S. Maria di Costantinopoli Church: overlap to Serlio model

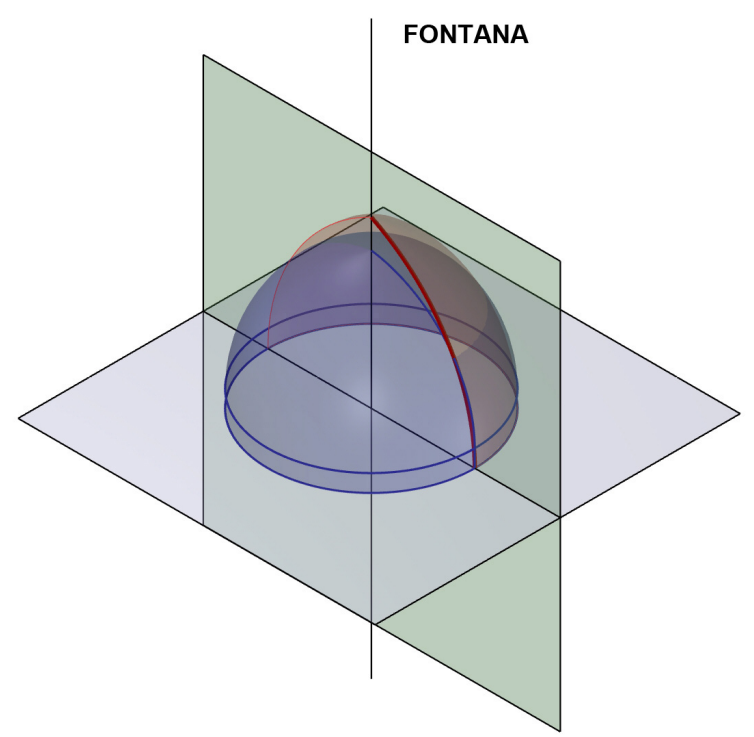

Figure 12. Napoli, S. Maria di Costantinopoli Church: overlap to Fontana model

In this way, the model is not unique, but is repeatable and editable in any step by simply changing the parameters The model is "intelligent" and can be adapted to many specific cases. Parameters are useful for describing the rules that determine the geometric shape of the object, the topological relation with other object in the model and constraints (Bruno 2017).

\section{PARAMETRIC MODELS FROM GEOMETRIC RULES: SHAPE GRAMMAR RESEARCH}

\subsection{Case study S. Maria di Costantinopoli Church in Naples}

Santa Maria of Costantinopoli Church is a 16th-century Roman Catholic church located in the historic center of Naples. In our research we are dealing with survey and data management problem in relation to domes geometry starting from computational approach.

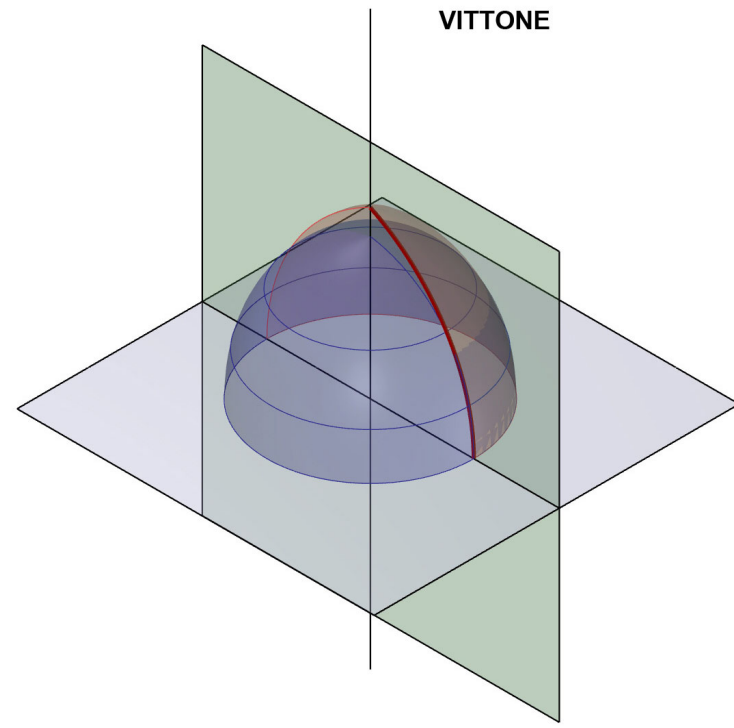

Figure 13. Napoli, S. Maria di Costantinopoli Church: overlap to Vittone model

The main goal is to generate parametric domes library based on the analysis of architectural books and shape grammar research from point cloud. We are going to test the use of this system in Historic Building Information Modelling (HBIM) process.

From a methodological point of view the pipeline can be summarize:

1. Data collection (point cloud);

2. Pre-Processing Survey Data (geometric analysis);

3. overlap objects library from historical data to reality-based 3D model;

4. analysis of results and definition of new procedural rules;

5. parametric model from new procedural rules:

6. integration of parametric objects library.

\subsection{Data collection and Data processing}

In our research we are testing the methodological process using data acquired from Image Based Modeling from Photogrammetry. The main critical aspects to take into account are the accuracy and the reliability of the survey data and the management of big data.

We are planning survey accuracy according to our specific purpose. We know that the quality of the survey defines the quality of the 3D model and, so, the quality of the analyses performed on it. There is a new parameter, that is "the Level of Reliabilit" (LOR), associated to the elements of the 3D model (Bianchini et al. 2018). It certifies the reliability of the data used for the model, the level of "pre-modelling" knowledge before further investigations.

We are able to produce a dense point cloud using survey tools that allow to collect 3D data automatically, but there are a lot of troubles in management of big data. For this reason we prefer to reduce the number of points even if we know that in this way we lose details that might not be generally accepted in historical heritage documentation.

One of the main goal of our research is to test different methods to balance level of detail and completeness with data manageability, considering the final purpose of the survey and the building characteristics.

We are designing the survey so that the resolution is adequate to the required level of detail. In order to have a manageable dataset we are going to test some of the algorithms that have 
been developed for point reduction according to some specific features of the object. The main aim is to preserve high resolution in rich detailed areas and delete redundant points in planar surfaces.

This part of research is in progress and the figures show only the methodological approach. At the end of this step we are going to have a point cloud of S. Maria di Costantinopoli dome that we can use to analyze analogies and differences with parametric model from historic rules.

\subsection{Geometric rules research}

One of the main goal of our research is to define the geometric rule to generate the S. Maria of Costantinopoli dome and to improve the set of parametric dome models based on new rules and data survey analysis. As we know, the S. Maria of Costantinopoli dome is revolution dome. In order to obtain the inside surface of dome we have to define the meridian curve revolving around the axis.

We oriented point cloud and we cut it with a vertical plane passing through the axis, in this way we obtained the meridian curve. We have generated the surface of revolution by rotating this curve (the generatrix) around vertical axis.

Mapping historical library objects, parametric models based on Serlio, Fontana and Vittone rules, with survey data we can observe that the $\mathrm{S}$. Maria of Costantinopoli is a dome generated by a pointed arch.

With regard to pointed-domes we have analyzed the methods illustrated by Carlo Fontana, by B.A. Vittone and by Vincenzo Scamozzi. There two different kind of "pointed domes": domes generated by polycentric arcs, "polycentric domes" from Fontana and Vittone rules, and domes generated by pointed arch. To generate this kind of domes we used rules by Scamozzi: the center of the arch can be located in $\mathrm{C}$ that can be $1 \backslash 3,1 \backslash 4$ or $1 \backslash 5$ of the diameter.

We have done the parametric model using this rule so that you can change the $\mathrm{C}$ location in relation to how many sections you divide the diameter.

The results analysis has shown that comparison between 3D model from point cloud and $3 \mathrm{D}$ realty based model must be done using meridian curve. We need an accurate profile to evaluate the arch feature. In this case we have to decide if the arch is a pointed arch or a polycentric arch.

\section{CONCLUSIONS}

The main objective of the research was to experiment with the use of parametric modeling as a tool for critical analysis aimed at the interpretation of big data, point clouds from laser scans or photogrammetry. We are going to use procedural modeling techniques to generate HBIM domes library.

Based on the current research problems and the potential of a procedural modelling approach (Dore 2017) we are working on: - designing a grammar of parametric shapes and objects that can be used to reconstruct domes geometry from point clouds;

- designing new procedural rules and algorithms for reconstructing domes geometry from point clouds;

- designing efficient methods of interactive editing to alter procedurally generated geometry

- implementing the grammar of shapes, procedural rules and methods for interactive geometry editing using Dynamo or Grashopper;

- using case studies to define the new procedural modelling tools.

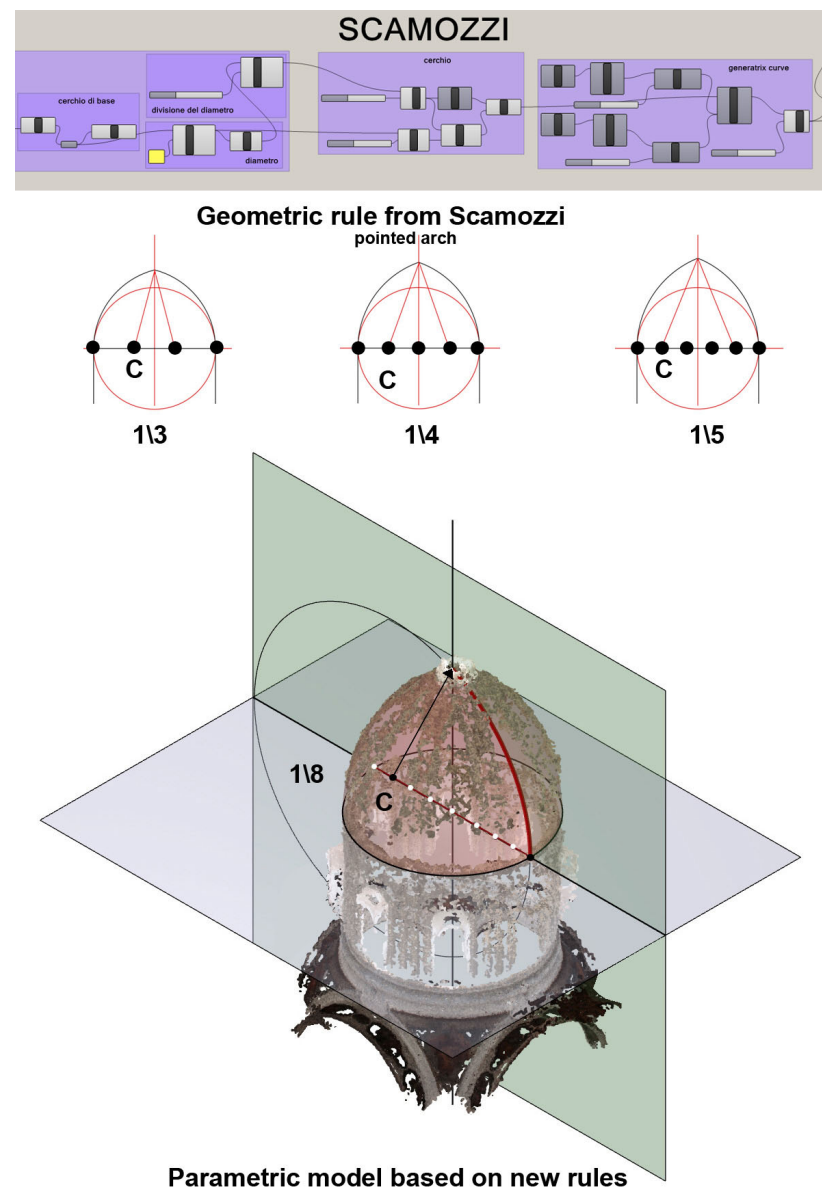

Figure 14. Design of new Parametric Shape Grammar Element

At present we have realized the parametric models based on the rules set by Sebastiano Serlio, Carlo Fontana, Bernardo Antonio Vittone and Vincenzo Scamozzi.

We are going to use procedural modeling techniques to generate HBIM domes library .

\section{REFERENCES}

Aubin, P. F., 2013. Renaissance Revit: Creating Classical Architecture with Modern Software. G3B Press.

Aveta, A., 2005. L'approccio multidisciplinare per la diagnosi dei dissesti strutturali di volte e cupole. In: Casiello, S. Le cupole in Campania. Indagini conoscitive e problematiche di conservazione. Napoli: Arte Tipografica.

Aveta C., 1980. Il "Dictionaire" e le tecniche costruttive in Violet le Duc e il restauro dei monumenti. Restauro, nn.47-4849.

Benvenuto, E., 1981. La scienza delle costruzioni e il suo sviluppo storico. Manuali Sansoni, Firenze.

Bianchi, G., Bruno, N., Dall'Asta, E., Forlani, G., Re, C., Roncella, R., Santise, M., Vernizzi, C., and Zerbi, A., 2016. Integrated survey for architectural restoration: a methodological comparison of two case studies. In: The International Archives of the Photogrammetry, Remote Sensing and Spatial Information Sciences, Vol. XLI (B5), pp. 175-182. 
Bianchini, C. 2016. Dal BIM all'H-BIM: un percorso tortuoso. In: Brainstorming Bim. Una giornata di dibattito sul modello BIM per le costruzioni antiche e nuove nella didattica, nella ricerca, per il trasferimento dell'innovazione, 25 November 2016, Milan, Italy.

Bianchini, C., Nicastro, S., 2018, La defnizione del Level of Reliability: un contributo alla trasparenza dei processi di Historic-BIM. In: Dienne, Building Information Modeling, Data \& Semantics

Bruno, N., 2015. From survey to analysis for Cultural Heritage management: a new proposal for database design in BIM, $\mathrm{Ph}$.D. thesis, Università di Parma. Dipartimento di Ingegneria e Architettura. [Viewed 20 December 2018]. Available from: http://dspace-unipr.cineca.it/handle/1889/3578

Di Luggo A., Scandurra S., 2016. La traduzione dal modello discreto al modello parametrico per la conoscenza del patrimonio architettonico nei sistemi HBIM. In: Disegnare con, Vol. 9, n.16. http://disegnarecon.univaq.it

Dore, C., 2017. Procedural Historic Building Information Modelling (HBIM) For Recording and Documenting European Classical Architecture. Ph.D. thesis, Dublin Institute of Technology. [Viewed 20 December 2018]. Available from: https://arrow.dit.ie/builtdoc/17/

Dore, C., Murphy, M., McCarthy, S., Brechin, F., Casidy, C., and Dirix, E. 2015a. Structural Simulations and Conservation Analysis -Historic Building Information Model (HBIM). In: The International Archives of the Photogrammetry, Remote Sensing and Spatial Information Sciences, Vol. XL-5/W4

Dore, C., Murphy, M., McCarthy, S., Brechin, F., Casidy, C., and Dirix, E., 2015b. Structural Simulations and Conservation Analysis -Historic Building Information Model (HBIM). In: 3D-Arch 2015 - 3D Virtual Reconstruction and Visualization of Complex Architectures (XL-5/W4), 25 - 27 February 2015, Avila, Spain.

Fontana, C., 1673. Dichiarazione dell'operato della cupola di Monte Fiascone colla difesa della censura. Manoscritto conservato nella Biblioteca Estense di Modena, Fondo Giuseppe Campori, Ms. g B.1.16. (in Hager, H., 1975. Die Kuppel des Domes in Montefiascone. $\mathrm{Zu}$ einem borrominesken Experiment von Carlo Fontana. In: Romisches Jahrbuch fur Kunstgeschichte, 15, pp. 143 - 168.)

Fontana, C., 1694. Il Tempio vaticano e la sua origine. Stamperia di Gio, Francesco Buagni, Roma, pp. 361 - 369.

Garagnani, S., 2013. Building Information Modeling and real world knowledge: A methodological approach to accurate semantic documentation for the built environment. proceedings of the Digital Heritage International Congress (DigitalHeritage), 28 October - 1 November 2013, Mareseille, France. DOI:10.1109/DigitalHeritage.2013.6743788

Inzerillo, L., Lo Turco, M., Parrinello, S., Santagati, C., and Valenti, G. M., 2016. BIM and architectural heritage: towards an operational methodology for the knowledge and the management of Cultural Heritage. In: Disegnare con, Vol. 9, n. 16

http://disegnarecon.univaq.it/ojs/index.php/disegnarecon/article/ view/153
Ippolito, L., 1997. Aspetti costruttivi e strutturali delle cupole toscane dei secoli XV e XVI. In: Conforti, C. ed. Lo specchio del cielo. Electa, Milano

Marconi, N., 1997. La teoria delle cupole nei trattati di architettura tra Seicento e Settecento. In: Conforti, C. ed. Lo specchio del cielo. Electa, Milano.

Migliari, R., Casale, A., Calvano, M., 2014. Sperimentazioni di architettura parametrica sulla Galleria Spada. In: Graziano Mario Valenti, ed. Prospettive architettoniche conservazione digitale, divulgazione e studio. VOLUME I. Sapienza Università Editrice, Roma, pp. 393 - 399.

Murphy, M., McGovern, E., and Pavia, S., 2013. Historic Building Information Modelling -Adding intelligence to laser and image based surveys Elsevier. In: ISPRS Journal of Photogrammetry and Remote Sensing https://www.academia.edu/5932333/HBIM.

Palladio, A., 1570. I Quattro Libri dell'Architettura. Libro I

Paris, L., Wahbeh, W., 2016. Survey and representation of the parametric geometries in HBIM In: Disegnare con, Vol. 9, n.16 $\mathrm{http} / / /$ disegnarecon.univaq.it/ojs/index.php/disegnarecon/article/ view/164

Serlio, S., 1584. I Sette libri dell'Architettura. Libro IV

Yang, X., Koehl, M., and Grussenmeyer, P., 2018. MESH-TOBIM: FROM SEGMENTED MESH ELEMENTS TO BIM MODEL WITH LIMITED PARAMETERS. In: ISPRS The International Archives of the Photogrammetry, Remote Sensing and Spatial Information Sciences, Vol. XLII-2, pp. 1213-1218, https://doi.org/10.5194/isprs-archives-XLII-2-1213-2018. 